\title{
Preparation of High Purity Cobalt by Anion Exchange and Floating Zone-Refining
}

\begin{abstract}
By M. Isshiki*, T. Kikuchi** and K. Igaki*
The anion exchange method and the floating zone-refining were applied to preparation of high purity cobalt. Effectiveness of the purification process was examined by the results of the atomic absorption analysis and the residual resistivity ratio (RRR). The anion exchange method was known to be effective for the elimination of main impurity elements in a commercial electrolytic cobalt, especially, $\mathrm{Fe}, \mathrm{Ni}$ and $\mathrm{Cu}$. The effectiveness of the floating zone-refining in a dry hydrogen atmosphere $(20 \mathrm{kPa})$ was clearly observed, and the highest value of RRR obtained was 225 .
\end{abstract}

(Received March 16, 1983)

\begin{abstract}
Keyzords: high purity cobalt, purification, anion exchange, floating zone-refining, residual resistivity ratio
\end{abstract}

\section{Introduction}

Purification of materials should be required for investigating the real properties of the materials and for preparing a well defined material. A few papers have been reported on the purification of cobalt. However, the highest purity previously reported is not sufficiently high compared with that obtained for other transition metals. The highest values of residual resistivity ratio (RRR) reported on iron, nickel and cobalt are $20100^{(1)}, 7000^{(2)}$ and $290^{(3)}$, respectively.

The present paper describes the effectiveness of the anion exchange method and the floating zone-refining. The former was applied to the purification of cobalt by Nardin ${ }^{(4)}$ and Dubois et $a l .^{(5)}$ They used electrolytic extraction to prepare metallic cobalt from the chloride solution previously purified by the anion exchange, and Nardin obtained 166 of the RRR value. Bourahla and Dubois ${ }^{(6)}$ carried out zonemelting of cobalt using a water cooled copper hearth after purification by the anion exchange and the electrolytic extraction. However, the RRR value slightly decreased through a coh-

* Department of Materials Science, Faculty of Engineering, Tohoku University, Aoba, Aramaki, Sendai 980, Japan.

** Graduate Student, Tohoku University. Present address: Furukawa Aluminium Co. Ltd. (Nikko Works), Kiyotaki, Sakuragaoka, Nikko-shi 32114, Japan. tamination after the zone-melting. The value of RRR measured on the specimen purified by the anion exchange and the electrolytic extraction was 213. The floating zone-melting has only been applied to the preparation of single crystals $^{(7)}$, and the effectiveness of the method on purification of cobalt has not been made clear.

On the other hand, Zukov and Kusaev ${ }^{(3)}$ performed the zone-melting of the eutectic of $\mathrm{CoCl}_{2}-\mathrm{NaCl}$ and prepared metallic cobalt by hydrogen reduction of the refined chloride. They obtained 290 of the RRR value, which was the highest value previously reported.

\section{Experimental Procedure}

As a starting material, a commercial electrolytic cobalt was used. The purification process finally adopted in this study consists of separa-

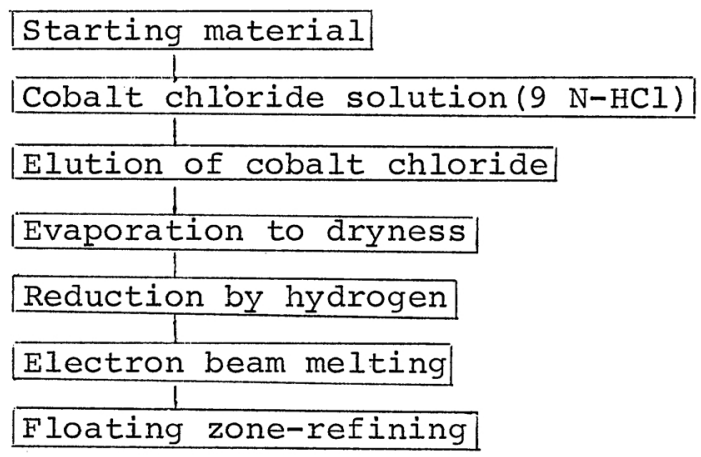

Fig. 1 Purification process of cobalt. 
tion by anion exchange, hydrogen reduction to metallic state, melting in vacuum $\left(10^{-3} \mathrm{~Pa}\right)$ by electron beam heating, melting in a dry hydrogen and floating zone-refining as shown in Fig. 1.

The starting material was dissolved electrolytically in $6 \mathrm{~N}-\mathrm{HCl}$, and the anion exchange separation was carried out in a medium of hydrochloric acid solution. The length and the diameter of a column made of an acrylic acid resin were 1000 and $70 \mathrm{~mm}$, respectively, in which a strong base anion exchange resin (Diaion SA10B) was packed to $700 \mathrm{~mm}$ in length. Special attention was paid to the chemical nature of the materials of which the apparatus was made. Teflon pipes, teflon valves, polyethylene tanks and some silica tubes were used to arrange the apparatus. More details of the anion exchange technique are given in a previous paper ${ }^{(8)}$.

Water purified by distillation after the ion exchange $\left(\rho>10^{5} \Omega \cdot \mathrm{m}\right)$ and an analytical grade hydrochloric acid were used in the present experiment. The purified solution was stored in a polyethylene tank.

The operation of the anion exchange separation consists of four steps, namely, fixing Co(II) on the resin in $9 \mathrm{~N}-\mathrm{HCl}$, washing out the impurities remaining in the space among the resin with $9 \mathrm{~N}-\mathrm{HCl}$, elution of $\mathrm{Co}(\mathrm{II})$ with $3 \mathrm{~N}-$ $\mathrm{HCl}$ and final elution of the strongly absorbed ions such as $\mathrm{Fe}(\mathrm{III})$ and $\mathrm{Zn}$ (II) with water for the subsequent operation. The charge solution for fixing was $15 \mathrm{~g} \mathrm{Co}(\mathrm{II}) / 1 \ell-9 \mathrm{~N}-\mathrm{HCl}$, and the flow rate of the charge solution and the eluant was $0.75 \mathrm{~cm}^{3} / \mathrm{s}(45 \mathrm{~m} \ell / \mathrm{min})$.

The cobalt chloride solution purified by the anion exchange was heated to dryness in a ceramic beaker, and the $\mathrm{CoCl}_{2}$ was reduced by dry hydrogen at $773 \mathrm{~K}$ for $18 \mathrm{ks}(5 \mathrm{~h})$. Pdpurified hydrogen was used as dry hydrogen. Cobalt powder obtained was formed into a bar with the cross section of about $8 \times 5 \mathrm{~mm}^{2}$ by an electron beam melter in vacuum $\left(10^{-3} \mathrm{~Pa}\right)$. Prior to the floating zone-refining, the cobalt bar was remelted in dry hydrogen to form the required shape (rod of $5 \mathrm{~mm}$ in diameter) in the floating zone-refining apparatus. The floating zone-refining was carried out in dry hydrogen of about $20 \mathrm{kPa}$. The length of zone pass $(L)$ and the molten zone $(w)$ were 100 and $5 \mathrm{~mm}$, respectively, and $L / w$ was 20 . The rate of the zone pass was $12 \mu \mathrm{m} / \mathrm{s}$.

The electrical resistivity was measured by the potential probe method at room temperature and liquid helium temperature directly on the floating zone-refined rod to derive the residual resistivity ratio.

\section{Results and Discussion}

The elution curve for the purification of cobalt chloride was shown in Fig. 2. Elements remarked, i.e., $\mathrm{Mn}, \mathrm{Pb}, \mathrm{Cu}, \mathrm{Fe}$ and $\mathrm{Zn}$ are the main impurity elements in the starting material. It should be noted that all the impurities except $\mathrm{Cu}$ can be removed effectively. Since the tails of $\mathrm{Co}$ and $\mathrm{Cu}$ peaks in the elution curve are overlapped, the cobalt chloride eluant was collected excluding the overlapped portion. Metallic cobalt was obtained in powder form by reducing the purified anhydrous cobalt chloride at $773 \mathrm{~K}$. In this case, contamination by $\mathrm{Si}^{(10)}$ from the silica tube used for reduction is considered not to occur because of the low temperature.

The floating zone-refining was carried out after the electron beam melting. Figure 3 shows the RRR profile measured on the cobalt rod floating zone-refined by 4 passes. In the figure, the length of horizontal broken lines means the distance between the two potential probes, and

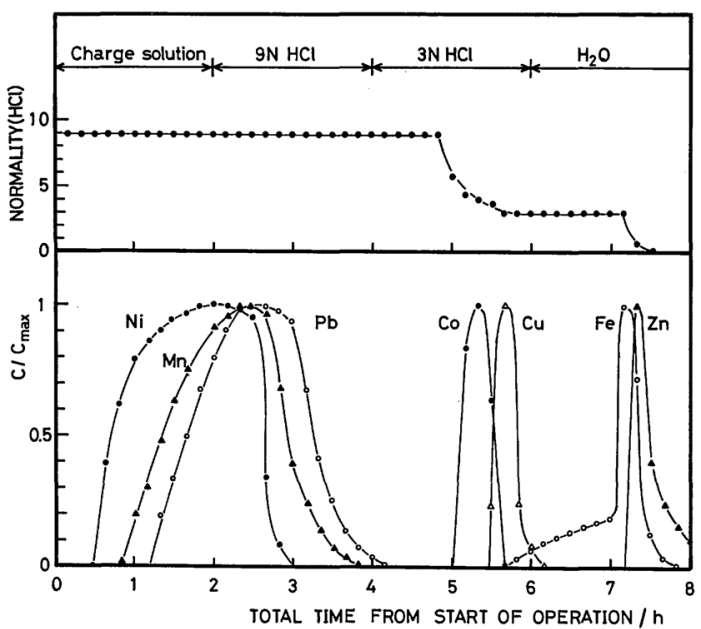

Fig. 2 Elution curve for the separation of cobalt chloride. 


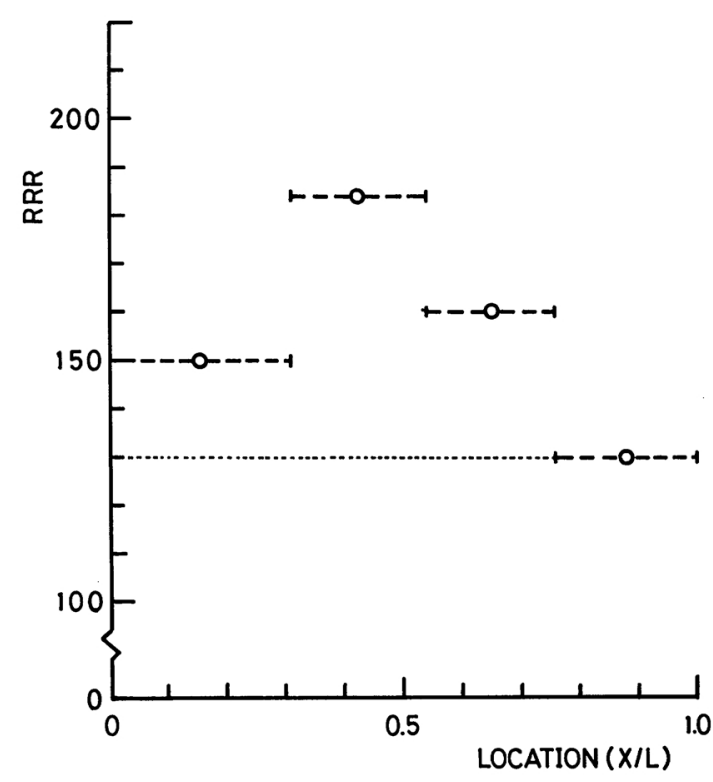

Fig. 3 RRR profile measured on the specimen floating zone-refined by 4 passes. $x / L$ is the fractional distance from the top of zone pass.

the mean values of $R R R$ are given by open circles. The RRR values of the starting material and the specimen purified only by the anion exchange were 48 and 130 , respectively. It should be noted that the floating zone-refining is very effective, and that almost all portions give RRR values higher than the value before the floating zone-refining. This fact cannot be explained only by the segregation effect. This may be due to the evaporation of the impurity elements with high vapor pressure or the elimination of non-metallic impurities such as carbon, nitrogen and oxygen through the reaction with hydrogen during the floating zone-refining under the reduced pressure of hydrogen $(20 \mathrm{kPa})$.

Since the overlap floating zone-refining has been found to be very effective for the purification of iron $^{(8)}$ and chromium ${ }^{(9)}$, the overlap floating zone-refining was applied also to cobalt for further purification. The starting point of the reverse passes was fixed at 0.52 in the value of $x / L$, taking into consideration the RRR profile shown in Fig. 3. If the reverse passes start at the position of larger $x / L$, the impurity elements with the distribution coefficient smaller than unity, which were already segre-

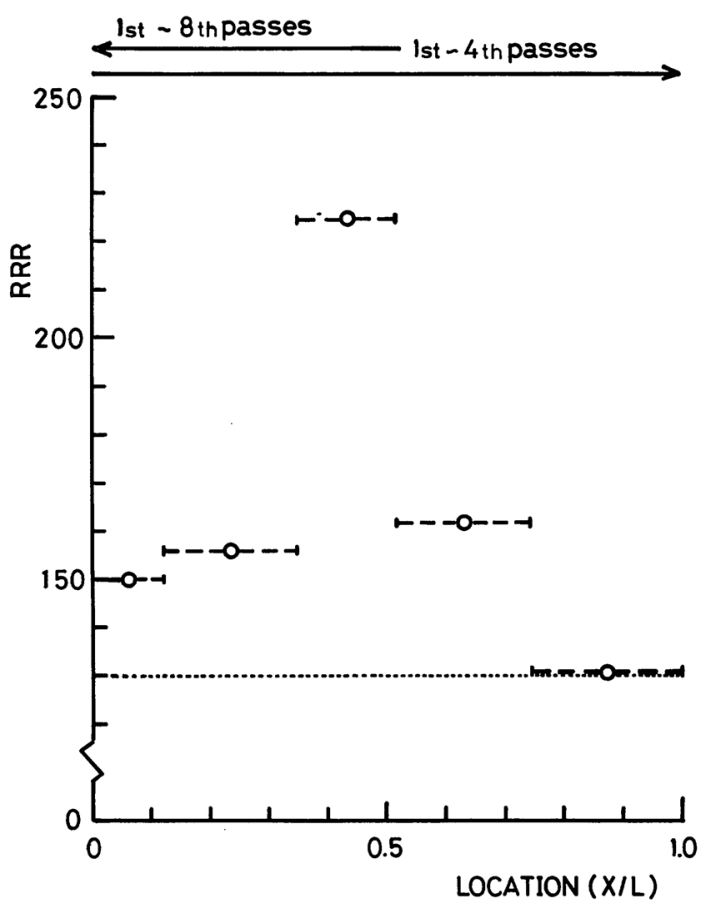

Fig. 4 RRR profile measured on the specimen overlap floating zone-refined.

gated toward the tail on the prior passes, would be dragged with the later reverse passes. The result of the overlap floating zone-refining is shown in Fig. 4. It is worth noting that the effectiveness of the overlap method is clearly observed as comfirmed on iron ${ }^{(8)}$ and chromium $^{(9)}$. The highest value is 225 , which is slightly larger than that reported by Bourahla and Dubois ${ }^{(6)}$.

Atomic absorption analysis of the impurity elements was carried out on the specimens at different purification steps. The results are given in Table 1 with data obtained on a commercial grade high purity cobalt wire of nominal purity of $99.998 \%$ supplied by Hale-Wood Co. Ltd. (H-W Co). The value of RRR measured on $\mathrm{H}-\mathrm{W}$ Co was 103 after annealing in vacuum $\left(10^{-3} \mathrm{~Pa}\right)$ for $86.4 \mathrm{ks}(24 \mathrm{~h})$.

The reliability of the atomic absorption data seems to be low for the trace impurity elements because of an interference from the cobalt ion of high concentration in the solution to be analyzed. However, the drastic decrease of the concentration of $\mathrm{Fe}, \mathrm{Ni}$ and $\mathrm{Cu}$ can be detected after the anion exchange separation. It should 
Table 1 Analysis of impurities by the atomic absorption.

(mass ppm)

\begin{tabular}{|c|c|c|c|c|c|}
\hline & $\begin{array}{l}\text { Starting } \\
\text { material }\end{array}$ & $\begin{array}{c}\text { After anion } \\
\text { exchange }\end{array}$ & $\begin{array}{l}\text { After electron } \\
\text { beam melting }\end{array}$ & $\begin{array}{l}\text { After floating } \\
\text { zone-refining }\end{array}$ & H-W Co \\
\hline $\mathrm{Fe}$ & 60 & 7 & 13 & 8 & 21 \\
\hline $\mathrm{Ni}$ & 2280 & 6 & 12 & 10 & 20 \\
\hline $\mathrm{Mn}$ & 3 & 3 & 3 & 3 & 3 \\
\hline $\mathrm{Cu}$ & 204 & 10 & 7 & 6 & 8 \\
\hline $\mathrm{Pb}$ & 24 & 14 & 19 & 8 & 19 \\
\hline $\mathrm{Zn}$ & 18 & 15 & 17 & 8 & 10 \\
\hline $\mathrm{Cr}$ & 9 & 5 & 7 & 10 & 10 \\
\hline
\end{tabular}

be noted that the cobalt specimen purified is purer than the $\mathrm{H}-\mathrm{W}$ Co, judging from both the analytical results and the residual resistivity ratio. It was found that some contaminations had occurred at the steps of the evaporation to dryness and the electron beam melting. For further purification, another contamination free reduction method and more reliable analytical method to examine the distribution of each impurity element are required. The electrolytic extraction adopted by Bourahla and Dubois ${ }^{(6)}$ is known to be effective for this purpose. Investigation on the electrolytic extraction and the proton activation analysis are under planning.

\section{Conclusion}

The effectiveness of the anion exchange method and the floating zone-refining has been confirmed by atomic absorption analysis and the measured RRR values. Especially, the anion exchange was found to be effective for the elimination of $\mathrm{Fe}, \mathrm{Ni}$ and $\mathrm{Cu}$. It is worth noting that the purification effect of the floating zonerefining on cobalt is confirmed for the first time. The highest value of RRR obtained in the present experiment is 225 , which is comparable to 213 reported by Bourahla and Dubois ${ }^{(6)}$.

It was known that a contamination free reduction process and an analytical method with high accuracy and low detection limit are required for further purification of cobalt.

\section{REFERENCES}

(1) M. Isshiki and K. Igaki: Trans. JIM, 19 (1978), 431.

(2) S. V. Plyushcheva, L. V. Malyarevich and C. V. Kopetskii: Izv. Akad. Nauk. SSSR Met., No. 6 (1976), 27.

(3) A. H. Zhukov and U. I. Kusaev: Izv. Akad. Nauk. SSSR Met., No. 4 (1978), 52.

(4) M. Nardin: C. R. Acad. Sc. Paris, C271 (1970), 1215.

(5) B. Dubois, F. Rocquet, M. Nardin and V. Q. Kinh: Mém. Sci. Rev. Mét., 66 (1969) 683.

(6) M. Bourahla and B. Dubois: C. R. Acad. Sc. Paris, C278 (1974), 679.

(7) S. Hayashi, J. Echigoya, H. Hariu, T. Sato, T. Nakamichi and M. Yamamoto: J. Cryst. Growth, 24/25 (1974) 422.

(8) M. Isshiki and K. Igaki: Trans. JIM, 18 (1977), 412.

(9) M. Isshiki, K. Arakawa, K. Igaki, A. Mizohata and T. Tsujimoto: J. Less-Common Metals, 96 (1984), 157.

(10) S. Takaki and H. Kimura: Scripta Met., 10 (1976) 701. 